AUGMENTN amodindowibontepotosim

Indications and Usage: AUGMENTIN* is indicated in the treatment of infections caused by suscept tile strains of the designated organisms in the conditions

Lower Respiratory Infections caused by $\beta$-lactamase-producing strains of Hemophilus influenzae and Branhamella catarrhalis.

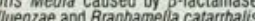

Sinusitis caused by $\beta$-lactamase-producing strains of Hemophilus influenzae and Branhamella catarnhalis

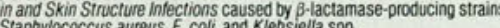
Urinary fract infections caused by $\beta$-lactamase-producing strains of $E$ collt

While AUGMENTIN is indicated only for the conditions listed above, infections caused by ampicillin susceptible organisms are also amenable to AUGMENTIN ampicillin ampicillin susceptible organisms and $\beta$-lactamase-producing organisms susce.
tible to AUGMENTIN should not require the addition of another antibiotic. Bacterioloogical studies, to determine the causative organisms and their susceptibility to AUGMENTIN. should be performed together with any indicated surgica
procedures. Drocedures.
Therapy may be instituted prior to obtaining the results from bacteriological and susceptibuity studies to determine the causative organisms and their susceptany of the $\beta$-lactamase-producing organisms listed above. Once the results are any own, the $\beta$-lactamas should be adjusted, if appropriate
known ARNINGS: SERIOUS AND OCCASIONALIY FATAL HYPERSENSITIVIITY ANAPHYLACTOID REACTIONS HAVE BEEN REPORTED IN PATIENIS ON
ENICILLIN THERAPY ALHOUGH ANAPHYLAXIS IS MORE FREOUENT FOL
OWWING PARENTERAL THERAPY IT HAS OCCURRED IN PATIENTS ON ORAL PENICILLINS. THESE REACTIONS ARE MOCCURRED IN IN PATIENTS ON ON ORALCUR IN INDIVIDU ALS WIIH A HISTOAY OF PENICILLIN HYPER SENSITIVITY AND OR A HIS
TORY OF SENSTIIVITY TO MUITIPLE ALLERGES THERE HAVE BEEN REPORTS OF INDIVIDUALS WITH A HISTORY OF PENICILLIN HYPEESENSITIVIIY WHO
HAVE EXPERIENCED SEVERE REACTIONS WHEN TREATED WITH CEPHALOSPORINS. BEFOAE INIIIATING THERAPY WITH ANY PENICILLIN CAREFUL
INOUIRY SHOULD BE MADE CONCERNING PREVIOUS HYPERSENSITIVITY REACTIONS TO PENICILLINS, CEPHALOSPORINS, OR OTHER ALLERGENS. IF AN ALLERGIC REACTION OCCURS. AUGMENTIN SHOULD BE DISCONTINUED
AND THE APPROPPIATE THERAPY INSTIIUTED SERIOUS ANAPHYLCTOID RINE. OXYGEN INTRAVENOUS STEROIDS. AND AIRWAY MANAGEMENT IN RINE. OXYGEN INTRAVENOUS STEROIDS. AND AIRWAY MANAGEMENT IN-
CLUDING INTUBATION SHOULD ALSO BE ADMINISTEREO AS INDICATED. Precautions: General: While AUGMENTIN possesses the characteristic low coxicity of the penicillin group of antibiotics. periodic assessment of organ system functions, including renal, hepatic and hematopoietic function is advis-
able during prolonged therapy A high percentage of patients with mononucleosis who receive ampicillin 10 patients with mononucleosis.

The possibility of superinfections with mycotic or bacterial pathopens should kept in mind during therapy if superinfections occur (usually involving cerapy instituted

Drug Interactions: Probenecid decreases the renal tubular secretion of amoxicillin
Concurrent use with AUGMENTIN may result in increased and prolonged blood Concurrent use with AUGMENTIN may result in increased and prolonged blood The concurrent administration of allopurinol and ampicillin increases substantially the incidence of rashes in patients receiving both drugs as compared to ampicillin rashes is due to alliogurinol or the hyperuriccemia presents in these patients here are no data with AUGMENTIN and allopurinol adoministered concurrently.
AUGMENTIN should not be 00 -administered with Antabuse (disulfiram). AUGMENTIN should not be co-administered with Antabuse ${ }^{\circ}$ (disulfiram)
Carcinogenesis, Mutagenesis, Impairment of Fertility: Long-term studies in Carcinogenesis, Mutagenesis, Impairment of Fertility: Long-term studies in ats at doses up to ten (10) times the human dose and have revealed no evidence of impaired fertility or harm to the fetus due to AUGMENTIN. There are, however no adequate and well-controlled studies in pregnant women. Because animal eproduction studies are not always predictive of human response, this drug should be used during pregnancy only if clearly needed.

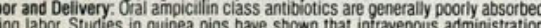
of ampicillin decreased the uterine tone, frequency of contractions, height of contractions and duration of contractions. However it is not known whether the Se of AUGMENTIN in humans during labor or delivery has immediate or delayed adverse effects on the fetus, prolongs the duration of labor or increases the

Nursing Mothers: Ampicillin class antibiotics are excreted in the milk; therefore. caution should be exercised when AUGMENTIN is administered to a nursing woman Adverse Reactions: AU GMENTIN is generally well tolerated. The majority of

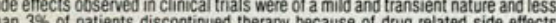
the $3 \%$ of patients discontinued therapy because of drug related side effects nausea $(3 \%)$, skin rashes and urticaria $(3 \%)$, vomiting $(1 \%)$, and vaginitis $(1 \%)$. The overail incidence of side effects, and in particular diarrnea, increased with the higher recommended dose, Other less frequently reported reactions include The following adverse reactions have been reported for ampicillin class ntibiotics: Diarthea nausea vomiting indigestion gastritis. stomatitis, glossitis. Gastrointestinal: Diarthea, nausea vomiting. indigestion, gastritis, stomatitis, glossitis
black haliry tongue, enterocolitis and pseudomembranous colitis. Hypersensitivity reactions: Skin rashes, urticaria, angioedema, serum sicknessand frequently fever), erythema multiforme (rarely Stevens. Johnson Synorome) reactions may be controlled with antihistamines and. if necessary, systemic unless the opinion of the physician dictates otherwise. Serious and occasional
latal hypersensitivity (anaphylactic) reactions can occur with oral penicillin (See

her. A moderate rise in SGOT and/or SGPT has been noted in patients treated with ampicillin class antibiotics as well as with AUGMENTIN, but the significance of these findings is unknown. As with some other penicillins, and some

ic and Lymphatic Systems; Anemia, thrombocytopenia, thrombocytopenic herapy with penicillins. These reactions are usually reversible on discontinuation of therapy and are believed to be hypersensitivity phenomena. A slight thrombocyrosis as noted in less than $1 \%$ of the patients treated with AUGMENTIN. Central Nervous System Reversible hyperactivity, aqitation, anxiety. insomnia,

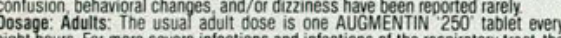
eright hours For more severe infections and infections of the respiratary tract, the OSE should be one AUGMENTIN ' 500 ' tablet every eight hours.

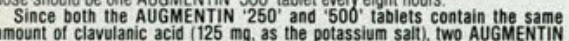
amount of clavulanic acid $125 \mathrm{mg}$, as the potassium salt), two AUGMENTIN 250 ' tablets are not equivalent to one AUGMENTIN ' 500 ' tablet Therefore, two
AUGMENTIN ' 250 ' tablets should not be substituted for one AUGMENTIN

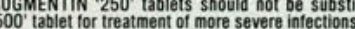

Children: The usual dose is $20 \mathrm{mg} / \mathrm{kg} /$ /day, based on amoxicillin component, in divided doses every eight hours For ottisis media. sinusitis and other more severe Infections, the dose should be $40 \mathrm{mg} / \mathrm{kg} /$ day, based on the amoxicillin component,
in divided doses every eight hours. Also available as AUGMENTIN ' 125 ' and Children weighing $40 \mathrm{~kg}$ and more should be dosed according to the adult commendations.

\section{Interferon-prednisone therapy for hepatitis B}

Patients with chronic hepatitis B were randomly assigned to one of the following regimens: prednisone for 6 weeks followed by 5 million units of recombinant interferon alfa-2b daily for 16 weeks; placebo followed by 5 million units of interferon daily for 16 weeks; placebo followed by 1 million units of interferon daily for 16 weeks; or observation with no treatment.

Hepatitis B e antigen and hepatitis B viral DNA disappeared from serum significantly more often in the patients given prednisone plus interferon ( 16 of 44 patients [36\%]) or 5 million units of interferon alone (15 of $41 \mathrm{pa}$ tients [37\%]) than in untreated control patients ( 3 of 43 patients [7\%]; $P<.001$ ). The difference between those patients given 1 million units of interferon and patients in the control group was not significant (7 of 41 [17\%]).

The amount of hepatitis B viral DNA in serum at entry to this study was the strongest independent predictor of a response to treatment $(P<.0001)$. Of the 38 patients who responded to interferon, $33(87 \%)$ had normal serum aminotransferase levels after therapy; 11 patients $(29 \%)$ who responded lost the hepatitis B surface antigen (HBsAg). None of the control subjects had this response. Blinded histologic assessment revealed a significant improvement in periportal necrosis in the treated patients $(P=.03)$

In chronic hepatitis $B$, treatment with interferon alfa- $2 \mathrm{~b}$ (5 million units per day for 16 weeks) effectively induced a sus- tained loss of viral replication. This treatment also induced remission, assessed biochemically and histologically, in more than one third of the patients. In approximately $10 \%$ of the patients treated with interferon, $\mathrm{HBsAg}$ disappeared from the serum. Despite this low incidence, this dramatic change in serologic status points to the need for earlier diagnosis and treatment of chronic hepatitis B.

Furthermore, a substantial percentage of patients, particularly those with high levels of viral replication, did not respond to treatment with inteferon alfa, either alone or following short-term corticosteroid therapy. For those patients who did respond to this therapy, long-term follow-up will be required to determine if the sustained viral replication loss persists. The rate of histologic progression and the occurrence of hepatocellular carcinoma must be determined long-term as well.

Perrillo RP, Schiff ER, Davis GL, et al: A randomized, controlled trial of interferon alfa-2b alone and after prednisone withdrawal for the treatment of chronic ht 'atitis B. N Engl J Med 1990;323:295301.

\section{Hyperparathyroidism in persons exposed to radiation during childhood}

Researchers conducted a cohort study involving 4297 patients who received radiation to the tonsils before the age of 16 years and who had been followed up prospectively. Among the 2923 patients who were located and provided information, 32 patients had clini(continued on page 779) 